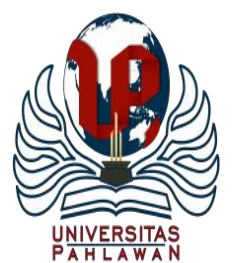

Edukatif : Jurnal Ilmu Pendidikan Volume 3 Nomor 4 Tahun 2021 Halm 2256 - 2264

EDUKATIF: JURNAL ILMU PENDIDIKAN

Research \& Learning in Education

https://edukatif.org/index.php/edukatif/index

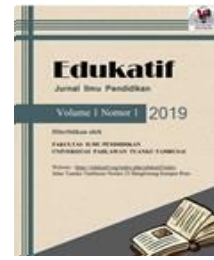

\title{
Hubungan Kompetensi Pedagogik Guru PAI dengan Kemandirian Belajar Siswa di Masa Pandemic Covid 19
}

\author{
Ari Sanusi ${ }^{1}$, Tajuddin Nur ${ }^{2}$, Astuti Darmiyanti ${ }^{3 凶}$ \\ Universitas Singaperbangsa Karawang, Indonesia ${ }^{1,2,3}$ \\ E-mail : arisanusi190@ gmail.com ${ }^{1}$, tajudin.nur@ fai.unsika.ac.id ${ }^{2}$, astusi.darmiyanti@ fai.unsika.ac.id $^{3}$
}

\begin{abstract}
Abstrak
Penelitian ini bertujuan untuk mengetahui hubungan kompetensi pedagogik PAI dengan kemandirian belajar siswa di masa pandemic Covid 19. Penelitian menggunakan pendekatan kuantitatif dengan metode korelasional. Sampel penelitian sebanyak 32 siswa kelas V SD Negeri 1 Pancawati kabupaten Karawang. Pengumpulan data menggunakan angket menggunakan aplikasi googleform. Analisis data mengguakan bantuan SPSS versi 25 mencakup analisis deskriptif, uji asumsi (uji normalitas dan uji linearitas), uji korelasi, dan uji determinasi. Hasil penelitian menunjukkan bahwa kompetensi pedagogik guru PAI adalah 3,61 dalam kondisi kategori baik. kemandirian belajar adalah 2,97 menunjukkan kemandirian belajar siswa dalam kondisi kategori cukup. Hasil uji signifikansi menunjukkan nilai signifikansi (2-tailed) $0,001<\alpha$ 0,05. Dengan demikian $\mathrm{H}_{\mathrm{a}}$ diterima dan $\mathrm{H}_{0}$ ditolak, maka terdapat hubungan hubungan kompetensi pedagogik PAI dengan kemandirian belajar. Nilai koefesien korelasi sebesar 0,832 menunjukkan adanya korelasi kuat dengan arah korelasi positif. Nilai koefisien determinasi sebesar 0,692 menunjukkan besarnya prosentase hubungan kompetensi pedagogik PAI dengan kemandirian belajar adalah sebesar 69,2\% sedangkan sisanya $29,8 \%$ ditentukan variabel lain.
\end{abstract}

Kata Kunci: Kompetensi Pedagogik, Pendidikan Agama Islam, Kemandirian Belajar

\begin{abstract}
This study aims to determine the relationship between PAI pedagogic competence and student learning independence during the Covid 19 pandemic. This study uses a quantitative approach with the correlational method. The research sample was 32 fifth-grade students of SD Negeri 1 Pancawati, Karawang district. Data collection using a questionnaire using the google form application. Data analysis using SPSS version 25 includes descriptive analysis, assumption test (normality test and linearity test), correlation test, and determination test. The results showed that the pedagogic competence of PAI teachers was 3.61 in the good category. learning independence is 2.97 independent learning independence insufficient condition. The results of the significance test showed a significance value (2-tailed) of $0.001<0.05$. Thus Ha is accepted and HO is rejected, then there is a relationship between PAI pedagogic competence and learning independence. The correlation coefficient value of 0.832 indicates a strong correlation with a positive correlation direction. The value of the coefficient of determination of 0.692 indicates that the percentage of the relationship between PAI pedagogic competence and learning independence is $69.2 \%$, while the remaining $29.8 \%$ is determined by other variables.
\end{abstract}

Keywords: Pedagogic Competence, Islamic Religious Education, Independent Learning

Copyright (c) 2021 Ari Sanusi, Tajuddin Nur, Astuti Darmiyanti

$\triangle$ Corresponding author:

Email : astusi.darmiyanti@ fai.unsika.ac.id

DOI $\quad$ : https://doi.org/10.31004/edukatif.v3i4.1185

ISSN 2656-8063 (Media Cetak)

ISSN 2656-8071 (Media Online)

Edukatif : Jurnal Ilmu Pendidikan Vol 3 No 4 Tahun 2021 p-ISSN 2656-8063 e-ISSN 2656-8071 
2257 Hubungan Kompetensi Pedagogik Guru PAI dengan Kemandirian Belajar Siswa di Masa Pandemic Covid 19 - Ari Sanusi, Tajuddin Nur, Astuti Darmiyanti

DOI: https://doi.org/10.31004/edukatif.v3i4.1185

\section{PENDAHULUAN}

Guru abad 21 merupakan sebuh profesi dengan pekerjaan yang kompleks dan sulit sejalan dengan perubahan besar dan cepat dalam lingkungan sekolah yang didorong oleh kemajuan ilmu pengetahuan dan teknologi, perubahan demografi, globalisasi dan lingkungan revolusi industry 4.0. Saat ini guru profesional bukan lagi hanya guru yang mampu mengajar dengan baik tetapi guru yang mampu menjadi pembelajar dan agen perubahan sekolah, serta mampu menjalin dan mengembangkan hubungan untuk meningkatkan kualitas pembelajaran di sekolah (Sudargini \& Purwanto, 2020).

Guru harus membekali diri dan menguasai kompetensi sebagai pendidik profesional (Anif et al., 2019). Guru juga dituntut lebih kreatif dalam mengembangkan pembelajaran agar siswa tidak merasa bosan dalam kegiatan pembelajaran. Menurut UU No.14 tahun 2005 tentang Guru dan Dosen dan PP 74 tahun 2008, pemerintah telah merumuskan empat jenis kompetensi guru sebagaimana tercantum dalam penjelasan peraturan pemerintah No.19 tahun 2005 tentang standar nasional pendidikan, yaitu: kompetensi pedagogik, kepribadian,profesional dan social (Apriani, 2016).

Kompetensi pedagogik merupakan kompetensi yang sangat penting dimiliki guru untuk mengarahkan siswa belajar (Sunhaji, 2014). Lebih lanjut dijelaskan kompetensi pedagogik adalah kompetensi guru yang terkait dengan kemampuan guru untuk mengelola atau menguasai pembelajaran, pemahaman peserta didik, pembelajaran manajemen, penggunaan IT, penggunaan model pembelajaran, pengembangan kurikulum dalam proses pembelajaran, evaluasi pembelajaran dan pengembangan potensi peserta didik dalam proses pembelajaran di kegiatan sekolah (Pahrudin et al., 2016).

Dalam situasi pandemic dengan pembelajaran secara virtual atau daring, tantangan pedagogis untuk dunia online dapat berupa penyedian pembelajaran yang lebih menuntut kolaborasi banyak pihak di sekolah dasar, seperti peran guru, peserta didik, dan orang tua (Burdina et al., 2019),. Namun sayangnya pelaksanaan belajar dari rumah selama masa pandemic ini mengalami beberapa permasalahan antara lain: a) siswa menganggap pembelajaran BDR sebagai libur panjang, b) tugas yang tidak terkontrol guru, c) pekerjaan rumah untuk siswa dikerjakan oleh orangtua, dan d) bahkan berdasarkan Forum Anak Nasional per April 2020, sekitar 58\% anak tidak menyukai kegiatan BDR (Firdaus et al., 2021).

Permasalahan BDR bahkan muncul secara spesifik pada pembelajaran PAI di kelas V SD Negeri 1 Pancawati kabupaten Karawang. Dalam pembelajaran PAI teridentifikasi permasalahan terkait kemandirian belajar siswa, antara lain: 1) siswa terlambat mengikuti pembelajaran, 2) siswa kesulitan fokus mengikuti pembelajaran, 3) siwa tidak mengikuti pembelajaran secara tuntas, 4) siswa abai mengerjakan tugas, 5) adapula siswa yang tugasnya dikerjakan oleh orangtua, 6) siswa mencontek jawaban teman, 7) siswa tidak memepersiapkan bahan ajar, 8) siswa tidak mencatat penjelasan guru, 9) siswa pasif dalam kegiatan diskusi dan tanya jawab, dan 10) siswa tidak peduli terhadap hasil belajar.

Guru dalam membimbing peserta didik harus merujuk kepada tujuan pendidikan nasional pasal 3 undang-undang sistem pendidikan nasional nomor 20 tahun 2003 yakni : Berkembangnya peserta didik agar menjadi manusia yang beriman dan bertaqwa kepada Tuhan Yang MahaEsa, berakhlak mulia, sehat berilmu, cakap, kreatif, mandiri, dan menjadi warga negara yang demokratis serta bertanggungjawab (Noor, 2018). Jadi sangat jelas bahwa salah satu tujuan pembelajaran PAI berdasarkan UU Sisdiknas adalah mengembangkan kemandirian belajar peserta didik (Bintang kejora et al., 2021).

Kemandirian belajar seseorang ditunjukkan dengan adanya kepercayaan diri akan kemampuannya dalam menyelesaikan berbagai macam permasalahan yang ada selama kegiatan belajar berlangsung, tanpa bantuan dari orang lain dan tidak ingin dikontrol pengambilan keputusannya untuk menyelesaikan permasalahan tersebut (Pratiwi \& Laksmiwati, 2016). Belajar mandiri adalah kegiatan belajar yang dilakukan peserta didik dengan sedikit atau sama sekali tanpa bantuan dari pihak luar bahkan, peserta didik dapat bertanggungjawab atas pembuatan keputusan yang berkaitan dengan proses belajarnya (Mulyaningsih, 2014). 
Sehingga belajar mandiri dibutuhkan motivasi yang kuat agar peserta didik dapat mengerjakan tugasnya secara mandiri. Motivasi itulah yang dapat mendorong timbulnya niat untuk belajar mandiri. Kemandirian belajar memiliki beberapa indikator diantaranya: a) inisiatif dan motivasi belajar intrinsik, b) kebiasaan mendiagnosa kebutuhan belajar sendiri, c) menetapkan tujuan/ target belajar, d) memonitor, mengatur, dan mengontrol belajar, e) memandang kesulitan sebagai tantangan, f) memanfaatkan dan mencari sumber bahan belajar yang relevan, g) memilih, dan menerapkan strategi belajar, h) mengevaluasi proses dan hasil belajar, dan i) self efficacy. Melalui belajar mandiri peserta didik dapat menggali potensi dalam dirinya sendiri karena dari belajar mandiri akan membangun pengetahuan yang sudah diketahui dan membentuk pengetahuan baru secara bertanggung jawab.

Beberapa penelitian lebih banyak membahas kajian mengenai kompetensi pedagogik dan hubungannya dengan hasil belajar ranah kognitif dengan fokus pada mata pelajaran sains. Penting dikaji sebuah penelitian yang secara spesifik mengenai kompetensi pedagogik dan korelasinya dengan kemandirian belajar para pambelajaran PAI di masa pandemic. Guru adalah aktor yang berkolaborasi dengan siswa mencapai tujuan pembelajaran secara optimal (Addin et al., 2020). Guru dengan kompetensi pedagogiknya akan sangat berkontribusi positif bagi perkembangan kemandirian anak di masa pendemic (Sabrina et al., 2020). Guru sebagai leader dan guide berperan penting dalam mengarahkan siswa untuk memiliki kemandirian belajar melalui reward \& punishment, aktivitas bertanya, diskusi, penugasan, media, methode, dan penciptaan lingkungan belajar yang efektif (Kejora, 2020). Melalui peran dan fungsinya, guru selalu mendapatkan kesempatan dan alasan kuat untuk memperbaiki segala hal berkaitan dengan pembelajaran termasuk di dalamnya membentuk kemandirian belajar siswa (Asmawati \& Bintang Kejora, 2020). Penelitian ini diharapkan dapat menjadi bahan pertimbangan bagi para akademisi, pendidik, dan peneliti dalam memperbaiki kualitas pembelajaran PAI di masa mendatang.

\section{METODE PENELITIAN}

Pendekatan penelitian ini menggunkaan pendekatan kuantitatif (Sugiyono, 2016). Penelitian kuantitatif merupakan penelitian yang menggunakan angka-angka yang dijumlahkan sebagai data kemudian dianalisis. Penelitian kuantitif menjelaskan fenomena dengan menggunakan data-data numerik yang dalam analisisnya menggunakan statistik untuk meringkas sejumlah besar data (Suharsaputra, 2012). Dalam penelitian kuantitatif, peneliti mengidentifikasi suatu permasalahan penelitian berdasarkan tren di bidang tersebut atau menjelaskan mengapa sesuatu terjadi (Creswell, 2014). Dalam penelitian ini desain penelitian menggunakan model one sample independent yaitu dengan satu variabel bebas dan satu variabel terikat (Sugiyono, 2015).

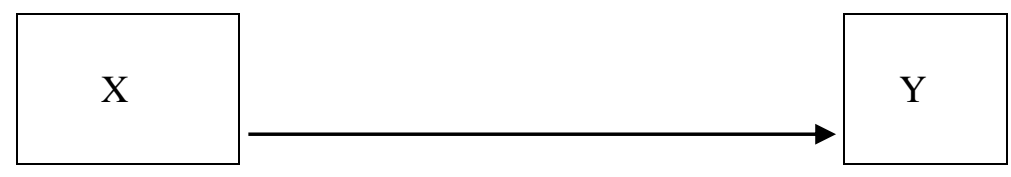

Gambar 1. Desain Penelitian

\section{Keterangan:}

$\mathrm{X}=$ Kompetensi pedagogik

$\mathrm{Y}=$ Kemandirian belajar

Penelitian melibatkan sampel 32 siswa kelas V SD Negeri 1 Pancawati kabupaten Karawang. Pengumpulan data menggunakan instrumen angket tertutup berskala Likert (1-5) berbantuan Google Classroom. Data dikumpulkan kemudian dilaakukan analisis deskriptif, uji asumsi (uji normalitas dan uji linearitas), uji korelasi, uji determinasi dan uji signifikansi. Analisis data dengan memanfaatkan aplikasi SPSS (Statistical Package for the Social Sciences) yang dapat membantu analisa statistik parametrik maupun non- 
2259 Hubungan Kompetensi Pedagogik Guru PAI dengan Kemandirian Belajar Siswa di Masa Pandemic Covid 19 - Ari Sanusi, Tajuddin Nur, Astuti Darmiyanti

DOI: https://doi.org/10.31004/edukatif.v3i4.1185

parametrik (Septiani \& Kejora, 2021). Untuk keperluan pengukuran dan interprestasi pada setiap indikator aspek yang diteliti digunakan pedoman sebagai berikut (Addin et al., 2020):

Tabel 1

Interprestasi

\begin{tabular}{ccccc}
\hline No & Rentang Nilai/Skor & $\%$ & \multicolumn{2}{c}{ Kriteria } \\
\hline 1. & $1,00-1,80$ & $20 \%-36 \%$ & Sangat Rendah & Sangat Tidak Setuju \\
\hline 2. & $1,81-2,60$ & $37 \%-52 \%$ & Rendah & Kurang Setuju \\
\hline 3. & $2,61-3,40$ & $53 \%-68 \%$ & Cukup & Cukup setuju \\
\hline 4. & $3,41-4,20$ & $69 \%-84 \%$ & Baik & Setuju \\
\hline 5. & $4,21-5,00$ & $83 \%-100 \%$ & Sangat Baik & Sangat Setuju \\
\hline
\end{tabular}

\section{HASIL DAN PEMBAHASAN PENELITIAN}

\section{Kompetensi Pedagogik Guru PAI}

Pengumpulan data variabel kompetensi pedagogik guru PAI dilaksanakan dengan melakukan survei angket secara online sebanyak 30 item dengan memanfaatkan googleform terhadap 32 siswa. Kompetensi pedagogic guru PAI dalam penelitian ini dikukur berdasarkan indikator yang diadopsi dari Permendiknas Nomor 16 tahun 2007 sebagai berikut (Darmiyanti, 2018): 1) Menguasai karakteristik peserta didik dari aspek fisik, moral, spiritual, sosial, kultural, emosional, dan intelektual. ; 2) Menguasai teori belajar dan prinsipprinsip pembelajaran yang mendidik.; 3) Menyelenggarakan pembelajaran yang mendidik yang disajikan oleh guru PAI; 4) Memanfaatkan teknologi informasi dan komunikasi untuk kepentingan pembelajaran PAI; 5) Memfasilitasi pengembangan potensi peserta didik untuk mengaktualisasikan berbagai potensi yang dimiliki; 6) Berkomunikasi secara efektif, empatik, dan santun dengan peserta didik dalam pembelaajaran PAI; dan 7) Menyelenggarakan penilaian dan evaluasi proses dan hasil belajar mata pelajaran PAI. Hasil pengumpulan data variabel kompetensi pedagogik guru PAI ditunjukkan sebagai berikut:

Tabel 2

Respon Siswa Terhadap Kompetensi Pedagogik Guru PAI

\begin{tabular}{clccc}
\hline No & \multicolumn{1}{c}{ Indikator } & $\begin{array}{c}\text { Rata- } \\
\text { Rata }\end{array}$ & $\%$ & Interprestasi \\
\hline 1 & $\begin{array}{l}\text { Menguasai karakteristik peserta didik dari aspek fisik, moral, } \\
\text { spiritual, sosial, kultural, emosional, dan intelektual }\end{array}$ & 3,3 & 66 & Cukup \\
\hline 2 & $\begin{array}{l}\text { Menguasai teori belajar dan prinsip-prinsip pembelajaran } \\
\text { yang mendidik }\end{array}$ & 3,82 & 76,4 & Baik \\
\hline 3 & $\begin{array}{l}\text { Menyelenggarakan pembelajaran yang mendidik yang } \\
\text { disajikan oleh guru PAI }\end{array}$ & 3,78 & 75,6 & Baik \\
\hline 4 & $\begin{array}{l}\text { Memanfaatkan teknologi informasi dan komunikasi untuk } \\
\text { kepentingan pembelajaran PAI }\end{array}$ & 3,62 & 72,4 & Baik \\
\hline 5 & $\begin{array}{l}\text { Memfasilitasi pengembangan potensi peserta didik untuk } \\
\text { mengaktualisasikan berbagai potensi yang dimiliki }\end{array}$ & 3,22 & 64,4 & Cukup \\
\hline 6 & $\begin{array}{l}\text { Berkomunikasi secara efektif, empatik, dan santun dengan } \\
\text { peserta didik dalam pembelaajaran PAI }\end{array}$ & 3,87 & 77,4 & Baik \\
\hline 7 & $\begin{array}{l}\text { Menyelenggarakan penilaian dan evaluasi proses dan hasil } \\
\text { belajar mata pelajaran PAI }\end{array}$ & 3,64 & 72,8 & Baik \\
\hline & $\quad$ Rata-Rata & 3,61 & 72,14 & Baik \\
\hline
\end{tabular}

Berdasarkan hasil pengolahan data survey kepada siswa, secara kumulatif rata-rata kompetansi pedagogik guru PAI adalah 3,61 dalam kondisi kategori baik. Berdasarkan data di atas diketahui siswa mengklaim bahwa guru perlu meningkatkan kemampuan pedagogiknya terutama pada 3 aspek yang masih dalam kategori cukup. Peningkatan kompetensi guru dapat dilakukan melalui kegiatan KKG, pelatihan dan supervisi (Kejora, 2019). 
2260 Hubungan Kompetensi Pedagogik Guru PAI dengan Kemandirian Belajar Siswa di Masa Pandemic Covid 19 - Ari Sanusi, Tajuddin Nur, Astuti Darmiyanti

DOI: https://doi.org/10.31004/edukatif.v3i4.1185

\section{Kemandirian Belajar}

Dalam penelitian ini pengukuran kemandirian belajar mengacu pada indicator yang dikemukakan oleh (Sari et al., 2021) dalam penelitiannya mencakup 1) ketidaktergantungan terhadap orang lain; 2) memiliki kepercayaan diri; 3) berperilaku disiplin; 4) memiliki rasa tanggung jawab; 5) berperilaku berdasarkan inisiatif sendiri; dan 6) melakukan kontrol diri. Hasil kemandirian belajar siswa kumulatif secara klasial ditunjukkan sebagai berikut:

Tabel 3

Respon Siswa Terhadap Kemandirian Belajar

\begin{tabular}{|c|c|c|c|c|c|}
\hline No & Indikator & & Rata-Rata & $\%$ & Interprestasi \\
\hline 1 & Ketidaktergantungan terhadap orang lain & & 2,56 & 51,2 & Rendah \\
\hline 2 & Memiliki kepercayaan diri & & 3,56 & 71,2 & Baik \\
\hline 3 & Berperilaku disiplin & & 2,58 & 51,6 & Rendah \\
\hline 4 & Memiliki rasa tanggung jawab & & 3,245 & 64,9 & Cukup \\
\hline 5 & Berperilaku berdasarkan inisiatif sendir & & 3,32 & 66,4 & Cukup \\
\hline \multirow[t]{2}{*}{6} & Melakukan kontrol diri. & & 2,54 & 50,8 & Rendah \\
\hline & & Rata-Rata & 2,97 & 59,35 & Cukup \\
\hline
\end{tabular}

Berdasarkan hasil pengolahan data survey, secara kumulatif rata-rata kemandirian belajar adalah 2,97 menunjukkan kemandirian belajar siswa dalam kondisi kategori cukup. Terdapat 5 orang siswa (16,6\%) memiliki kemandirian sangat tinggi, 7 orang siswa $(21,87 \%)$ dengan kemandirian tinggi, 12 orang siswa $(37,5 \%)$ dengan kemandirian cukup, 5 orang siswa $(15,6 \%)$ dengan kemandirian rendah, dan 3 orang siswa $(9,37 \%)$ dengan kemandirian sangat rendah.

Hasil analisis data secara deskriptif juga menunjukkan dari enam indicator kemandirian belajar yang diukur, hanya satu indicator dalam kategori baik atau tinggi yaitu pada aspek kepercayaan diri. Tiga indikator dalam kategori cukup dan dua indikator dalam kategori rendah. Artinya perlu dilakukan upaya meningkatan kemandirin belajar pada lima aspek agar siswa memiliki sikap ketidaktergantungan terhadap orang lain, berperilaku disiplin, memiliki rasa tanggung jawab, berperilaku berdasarkan inisiatif sendiri, dan mampu melakukan kontrol diri.

\section{Hubungan Kompetensi Pedagogik Guru PAI dengan Kemandirian Belajar}

Tahap selanjutnya adalah tahap pengujian hipotesis hubungan kompetensi guru PAI dengan kemandirina belajar siswa. Hipotesis yang diajukan sebagai berikut:

$\mathrm{H}_{0} \quad$ : Tidak terdapat hubungan kompetensi pedagogik PAI dengan kemandirian belajar.

$\mathrm{H}_{\mathrm{a}} \quad$ : Terdapat terdapat hubungan kompetensi pedagogik PAI dengan kemandirian belajar.

Tahapan awal melakukan uji hipotesis, dilakukan uji asumsi atau uji persyaratan analisis berupa uji normalitas dan uji linearitas data.

Tabel 4. Uji Asumsi

\begin{tabular}{|c|c|c|c|c|c|}
\hline \multirow[b]{2}{*}{ No } & \multirow[b]{2}{*}{ Variabel } & \multicolumn{2}{|c|}{ Uji Normalitas } & \multicolumn{2}{|c|}{ Uji Homogenitas } \\
\hline & & $\begin{array}{l}\text { Asymp. Sig. } \\
\text { (2-tailed) }\end{array}$ & Hasil & $\begin{array}{l}\text { Asymp. Sig. } \\
\text { (2-tailed) }\end{array}$ & Hasil \\
\hline 1 & $\begin{array}{l}\text { Kompetensi Pedagogik } \\
\text { Guru PAI }\end{array}$ & 0,218 & Normal & 0,913 & Linear \\
\hline 2 & Kemandirian Belajar & 0,132 & Normal & & \\
\hline
\end{tabular}

Hasil uji normalitas menunjukkan data variabel kompetensi pedagogik PAI (sig. 0,218> $\alpha 0,05)$ dan kemandirian belajar (sig. 0,132 > $\alpha 0,05$ ) berdistribusi normal. Hasil uji linearitas kedua data variable pun menunjukkan hasil linear (sig. 0,913> $>0,05$ ). Dengan terpenuhinya syarat normalitas dan linearitas, maka uji hipotesis menggunakan uji parametrik. 
2261 Hubungan Kompetensi Pedagogik Guru PAI dengan Kemandirian Belajar Siswa di Masa Pandemic Covid 19 - Ari Sanusi, Tajuddin Nur, Astuti Darmiyanti

DOI: https://doi.org/10.31004/edukatif.v3i4.1185

Tabel 5

Koefisien Korelasi

\begin{tabular}{l|l|c|c}
\hline \multicolumn{4}{c}{ Correlations } \\
\hline \multirow{2}{*}{ Kompetensi } & \multicolumn{1}{|c}{ kemandirian } & Hasil Belajar \\
\cline { 2 - 4 } & Pearson Correlation & 1 & .001 \\
\cline { 2 - 4 } & Sig. (2-tailed) & & .832 \\
\cline { 2 - 4 } & $\mathrm{N}$ & 32 & 32 \\
\hline Kemandirian Belajar & Pearson Correlation & .001 & 1 \\
\cline { 2 - 4 } & Sig. (2-tailed) & .832 & 32 \\
\cline { 2 - 4 } & $\mathrm{N}$ & 32 & 32 \\
\hline
\end{tabular}

Hasil analisa korelasi dengan menggunakan Correlations Product Moment Pearson menunjukkan nilai signifikansi (2-tailed) 0,001 $<\alpha$ 0,05. Dengan demikian $\mathrm{H}_{\mathrm{a}}$ diterima dan $\mathrm{H}_{0}$ ditolak, maka terdapat hubungan hubungan kompetensi pedagogik PAI dengan kemandirian belajar. Nilai koefesien korelasi sebesar 0,832 menunjukkan adanya korelasi kuat dengan arah korelasi positif. Artinya apabila kompetensi pedagogik guru PAI ditingkatkan kualitasnya, maka kemandirian belajar siswa juga akan meningkat. Demikian pula sebaliknya, apabila kompetensi pedagogik guru PAI dalam kualitas rendah, kemandirian belajar siswa juga akan menurun.

Tabel 6

Koefisien Determinasi

\begin{tabular}{l|c|c|c|c}
\hline \multicolumn{5}{c}{ Model Summary } \\
\hline Model & $\mathrm{R}$ & $\mathrm{R}$ Square & $\begin{array}{c}\text { Adjusted R } \\
\text { Square }\end{array}$ & $\begin{array}{c}\text { Std. Error of the } \\
\text { Estimate }\end{array}$ \\
\hline 1 & $.832^{\mathrm{a}}$ & .692 & .443 & 4.619 \\
\hline \multicolumn{5}{|c}{ a. Predictors: (Constant), kemandirian } \\
\hline
\end{tabular}

Hasil uji determinasi menunjukkan nilai $\mathrm{R}(0,832)$ dengan $\mathrm{R}^{2}(0,692)$. Koefisien determinasi sebesar 0,692 menunjukkan besarnya prosentase hubungan kompetensi pedagogik PAI dengan kemandirian belajar adalah sebesar $69,2 \%$. Hasil penelitian penulis menunjukkan adanya korelasi signifikan sebesar $69,2 \%$ kompetensi pedagogik PAI dengan kemandirian belajar. Beberapa penelitian telah dilakukan namun lebih mengarah kepada hasil beajar. Artinya hasil penelitian ini diharapkan dapat memperkaya khazanah penelitian dan karya ilmiah di bidang pendidikan.

Rafika et al., (2017) dalam penelitiannya menjelaskan upaya guru dalam mengoptimalkan dan menumbuhkan kemandirian belajar siswa yang dilakukan dengan memotivasi dan penciptaan suasana belajar yang menyenangkan. Untuk memotivasi siswa, guru melakukan dengan cerita, tanya jawab, teka-teki, nyanyian, memberikan contoh-contoh tentang kenyataan atau pengalaman yang terjadi dalam kehidupan sehari-hari sebagai perbandingan antara keberhasilan dan kegagalan. Menumbuhkan rasa senang dalam belajar dilakukan dengan belajar sambil bermain, menggunakan alat peraga yang sesuai dengan bahan ajar, melakukan relaksasi setelah belajar, memberi pujian, hadiah, menerapkan pembelajaran PAKEM menggunakan multi metode dan multi media. Dalam membuat perencanaan mata pelajaran semua guru menggunakan metode pembelajaran yaitu ceramah, diskusi, demostrasi, tanya jawab, dan penugasan.

Kemandirian belajar sangat penting bagi siswa dalam upaya meminimalisir fenomena-fenomena belajar yang kurang mandiri, seperti : tidak betah belajar lama di kelas atau belajar hanya menjelang ujian, membolos, menyontek, pasif di dalam kelas. Kemandirian belajar akan terwujud apabila siswa aktif mengontrol sendiri segala sesuatu yang dikerjakan, mengevaluasi dan selanjutnya merencanakan sesuatu yang lebih dalam pembelajaran yang dilalui dan siswa mau aktif di dalam proses pembelajaran yang ada. Dengan terwujudnya 
2262 Hubungan Kompetensi Pedagogik Guru PAI dengan Kemandirian Belajar Siswa di Masa Pandemic Covid 19 - Ari Sanusi, Tajuddin Nur, Astuti Darmiyanti

DOI: https://doi.org/10.31004/edukatif.v3i4.1185

kemandirian belajar yang baik tentunya akan memberikan kontribusi yang cukup signifikan bagi peningkatan prestasi belajar siswa (Suhendri, 2011).

Ali dan Asrori (Widianti, 2020) menyebutkan sejumlah faktor yang mempengaruhi perkembangan kemandirian, yaitu :

1) Gen atau keturunan orangtua. Orang tua memiliki sifat kemandirian tinggi sering kali menurunkan anak yang memiliki kemandirian juga.

2) Pola asuh orang tua. Cara orang tua mengasuh dan mendidik anak akan mempengaruhi perkembangan kemandirian anak remajanya.

3) Sistem pendidikan di sekolah. Proses pendidikan di sekolah yang tidak mengembangkan demokrasi pendidikan dan cenderung menenkankan indoktrinasi tanpa argumentasi akan menghambat perkembangan kemandirian remaja sebagai peserta didik

4) Sistem kehidupan di masyarakat. Sistem kehidupan masyarakat yang terlalu menekankan pentingnya hierarki struktur sosial, merasa kurang aman atau mencekam serta kurang menghargai manifestasi potensi remaja dalam kegiatan produktif dapat menghambat kelancaran perkembangan kemandirian remaja atau peserta didik.

Faktor-faktor yang mempengaruhi di atas kemandirian sangat menentukan sekali tercapainya kemandirian seseorang, begitu pula dengan kemandirian belajar peserta didik dipengaruhi oleh faktor dari dalam diri peserta didik itu sendiri, maupun yang berasal dari luar yaitu lingkungan keluarga, sekolah, lingkungan sosial ekonomi dan lingkungan masyarakat (Rahman et al., 2021). Guru sebagai pendidik dan teladan bagi siswa mempunyai peranan yang sangat penting dalam membentuk dan meningkatkaan kemandirian siswa melalui interaksi belajar-mengajar. Kemandirian ini perlu dibangun melalui pembiasaan mengingat kemandirian belajar merupakan modal utama bagi tahapan perkembangan belajar siswa Dengan demikian, penulis berpendapat dalam mencapai kemandirian seseorang tidak lepas dari faktor kompetensi pedagigik guru dalam melakukan aktivitas belajar atau kegiatan belajar sehari-hari di dalam lingkungan pendidikan.

\section{KESIMPULAN}

Selama diberlakukannya pandemic Covid-19 pembelajaran PAI kelas V SD Negeri 1 Pancawati kabupaten Karawang dilaksanakan secara daring/online. Kemandirian belajar siswa menjadi masalah dalam pembelajaran daring. Guru dengan kompetensi pedagogiknya akan sangat berkontribusi positif bagi perkembangan kemandirian anak di masa pendemic. Hasil penelitian menunjukkan kompetensi pedagogik guru berkorelasi positif dengan perkembangan kemandirian siswa. Artinya apabila kualitas kompetensi guru baik, maka siswa pun akan memiliki perkembangan atau peningkatan kemandirian yang baik. Begitu pula sebaliknya jika kualitas kompetensi pedagogic guru rendah, maka siswa pun akan memiliki perkembangan atau peningkatan kemandirian yang rendah pula. Uji hipotesis menunjukkan nilai signifikansi (2-tailed) 0,001 $<\alpha$ 0,05. Dengan demikian Ha diterima dan H0 ditolak, maka terdapat hubungan hubungan kompetensi pedagogik PAI dengan kemandirian belajar. Nilai koefesien korelasi sebesar 0,832 menunjukkan adanya korelasi kuat dengan arah korelasi positif. Hasil uji determinasi menunjukkan nilai R $(0,832)$ dengan R2 $(0,692)$. Koefisien determinasi sebesar 0,692 menunjukkan besarnya prosentase hubungan kompetensi pedagogik PAI dengan kemandirian belajar adalah sebesar 69,2\%. Hasil penelitian penulis menunjukkan adanya korelasi signifikan sebesar 69,2\% kompetensi pedagogik PAI dengan kemandirian belajar.

\section{DAFTAR PUSTAKA}

Addin, F. N., Bintang Kejora, M. T., \& Kosim, A. (2020). Pengaruh Kepemimpinan Transformasional Kepala Madrasah Terhadap Kinerja Guru Di Madrasah Aliyah Ghoyatul Jihad Kabupaten Karawang. Idaarah: Jurnal Manajemen Pendidikan, 4(2), 153. https://doi.org/10.24252/idaarah.v4i2.16673 
2263 Hubungan Kompetensi Pedagogik Guru PAI dengan Kemandirian Belajar Siswa di Masa Pandemic Covid 19 - Ari Sanusi, Tajuddin Nur, Astuti Darmiyanti

DOI: https://doi.org/10.31004/edukatif.v3i4.1185

Anif, S., Sutama, Prayitno, H. J., \& Idrus, N. B. M. (2019). Effectiveness of pedagogical competence: A development model through association of biology teachers' forum. Jurnal Pendidikan IPA Indonesia, 8(1), 22-31. https://doi.org/10.15294/jpii.v8i1.17176

Apriani, E. (2016). A New Literacy: The Role of Technology to Develop Student's Character. Ta'dib, 21(1), 59. https://doi.org/10.19109/td.v21i1.742

Asmawati, E., \& Bintang Kejora, M. T. (2020). The Effect of Using Simple Aircraft Concrete Media on the Mastery of Concepts in Inquiry Science Learning in Elementary School Students. MUDARRISA: Jurnal Kajian Pendidikan Islam, 12(2), 150-168. https://doi.org/10.18326/mdr.v12i2.150-168

Bintang kejora, M. T., Junaedi Sitika, A., \& Syahid, A. (2021). Penguatan Pendidikan Karakter Berbasis Humanistik Melalui Kearifan Lokal dan Nilai Pendidikan Islam Pada Anak Panti Asuhan. 19, 112.

Burdina, G. M., Krapotkina, I. E., \& Nasyrova, L. G. (2019). Distance learning in elementary school classrooms: An emerging framework for contemporary practice. International Journal of Instruction, 12(1), 1-16. https://doi.org/10.29333/iji.2019.1211a

Creswell, J. W. (2014). Research Design Qualitative, Quantitative, and Mixed Method Approaches. SAGE Publication. Inc.

Darmiyanti, A. (2018). Islamic Parenting Pada Anak Usia Dini (Studi Analisis Buku Islamic Parenting Karya Syaikh Jamaal ’Abdurrahman). Jurnal JPI-Rabbani, 2(9), 1689-1699.

Firdaus, F. M., Pratiwi, N. A., Riyani, S., \& Utomo, J. (2021). Meningkatkan kemandirian belajar peserta didik sekolah dasar menggunakan Model SOLE saat pandemi Covid-19. 12(1), 1-8.

Kejora, M. T. B. (2019). Pengaruh Kepemimpinan Transformasional Kepala Sekolah Terhadap Kinerja Guru. Jurnal Wahana Karya Ilmiah, 3(2), 364-384.

Kejora, M. T. B. (2020). The Use of Concrete Media in Science Learning in Inquiry to Improve Science Process Skills for Simple Machine subject. MUDARRISA: Jurnal Kajian Pendidikan Islam, 12(1), 1-17. https://doi.org/10.18326/mdr.v12i1.1-17

Mulyaningsih, I. E. (2014). Pengaruh Interaksi Sosial Keluarga, Motivasi Belajar, dan Kemandirian Belajar terhadap Prestasi Belajar. Jurnal Pendidikan Dan Kebudayaan, 20(4), 441. https://doi.org/10.24832/jpnk.v20i4.156

Noor, T. (2018). Rumusan Tujuan Pendidikan Nasional Pasal 3 Undang-Undang Sistem Pendidikan Nasional No 20 Tahun 2003. Wahana Karya Ilmiah Pendidikan, 2(1), 123-144.

Pahrudin, Martono, T., \& Murtini, W. (2016). The Effect of Pedagogic Competency, Personality, Professional and Social Competency Teacher to Study Achievement of Economic Lesson in State Senior High School of East Lombok District Academic Year 2015/2016. The 2nd International Conference on Teacher Training and Education Sebelas Maret University, 2(1), 332-345.

Pratiwi, I. D., \& Laksmiwati, H. (2016). Kepercayaan Diri dan Kemandirian Belajar Pada Siswa SMA Negeri "X." Jurnal Psikologi Teori Dan Terapan, 7(1), 43. https://doi.org/10.26740/jptt.v7n1.p43-49

Rafika, Israwati, \& Bachtiar. (2017). Upaya Guru Dalam Menumbuhkan Kemandirian Belajar Siswa di SD Negeri 22 Banda Aceh. Jurnal Ilmiah Pendidikan Guru Sekolah Dasar, 2, 115-123. https://media.neliti.com/media/publications/187538-ID-upaya-guru-dalam-menumbuhkankemandirian.pdf

Rahman, U., Idris, R., Majid, A. F., \& Sulasteri, S. (2021). The Influence of Interest and Independence of Learning on Student Math Learning Outcomes Pengaruh Minat dan Kemandirian Belajar Terhadap Hasil Belajar. 3(1), 24-37.

Sabrina, F. F., Darmiyanti, A., \& BK, M. T. (2020). Kompetensi Manajerial Kepala Sekolah Untuk Meningkatkan Mutu Guru. Idaarah: Jurnal Manajemen Pendidikan, 4(2), 239.

https://doi.org/10.24252/idaarah.v4i2.16740

Edukatif : Jurnal Ilmu Pendidikan Vol 3 No 4 Tahun 2021 p-ISSN 2656-8063 e-ISSN 2656-8071 
2264 Hubungan Kompetensi Pedagogik Guru PAI dengan Kemandirian Belajar Siswa di Masa Pandemic Covid 19 - Ari Sanusi, Tajuddin Nur, Astuti Darmiyanti

DOI: https://doi.org/10.31004/edukatif.v3i4.1185

Sari, P. P., Hidayah, N., Najibufahmi, M., \& Pekalongan, U. (2021). Pengaruh Kemandirian dan Kreativitas Belajar terhadap Prestasi Belajar Matematika dalam Pembelajaran Daring. Jurnal Pendidikan Matematika, 01(01), 71-82.

Septiani, A., \& Kejora, M. T. B. (2021). Tingkat Aktivitas Belajar Siswa pada Pembelajaran Online Pendidikan Agama Islam di Masa. EDUKATIF : JURNAL ILMU PENDIDIKAN 3(5), 2594-2606.

Sudargini, Y., \& Purwanto, A. (2020). the Effect of Teachers Pedagogic Competency on the Learning Outcomes of Students. Journal of Industrial Engineering \& Management Research ( Jiemar), 1(4), 2722-8878. https://doi.org/10.7777/jiemar

Sugiyono. (2015). Metode Penelitian Pendidikan Pendekatan Kuantitatif, Kualitatif, dan R\&D. Alfabeta.

Sugiyono. (2016). Metode Penelitian Kombinasi (Mix Methode). Alfabeta.

Suharsaputra, U. (2012). Metode Penelitian Kuantitaif Kualitatif dan Tindakan. Refika Adhitama.

Suhendri, H. (2011). Pengaruh Kecerdasan Matematis-Logis dan Kemandirian Belajar terhadap Hasil Belajar Matematika. Formatif: Jurnal Ilmiah Pendidikan MIPA, 1(1), 29-39. https://doi.org/10.30998/formatif.v1i1.61

Sunhaji, S. (2014). Konsep Manajemen Kelas Dan Implikasinya Dalam Pembelajaran. Jurnal Kependidikan, 2(2), 30-46. https://doi.org/10.24090/jk.v2i2.551

Widianti, M. (2020). Pengaruh Kemandirian Belajar Terhadap Prestasi Belajar Bahasa Indonesia Pada Siswa Kelas Xi Sma Di Kota Depok Jawa Barat. LITERASI: Jurnal Ilmiah Pendidikan Bahasa, Sastra Indonesia Dan Daerah, 10(Volume 10), 42-53. https://doi.org/10.23969/literasi.v10i1.2052 